Article

\title{
Electrohydrodynamic Atomization for Minimum Quantity Lubrication (EHDA-MQL) in End Milling Ti6A14V Titanium Alloy
}

\author{
Andrea De Bartolomeis and Alborz Shokrani * \\ Department of Mechanical Engineering, University of Bath, Bath BA2 7AY, UK; adb66@bath.ac.uk \\ * Correspondence: a.shokrani@bath.ac.uk; Tel.: +44-1225-38-6588
}

Received: 12 June 2020; Accepted: 10 July 2020; Published: 13 July 2020

check for updates

\begin{abstract}
Titanium alloy Ti6Al4V is a difficult-to-machine material which is extensively used in the aerospace and medical industries. Machining titanium is associated with a short tool life and low productivity. In this paper, a new cooling-lubrication system based on electrohydrodynamic atomization was designed, manufactured and tested and the relevant theory was developed. The major novelty of the system lies within the use of electrohydrodynamic atomization (EHDA) and a three-electrode setup for generating lubricant droplets. The system was tested and compared with that of flood, minimum quantity lubrication (MQL) and compressed air machining. The proposed system can extend the tool life by 6 and 22 times when compared with MQL and flood cooling, respectively. This is equivalent to more than $170 \mathrm{~min}$ tool life at $120 \mathrm{~m} / \mathrm{min}$ cutting speed allowing for significant productivity gains in machining Ti6Al4V.
\end{abstract}

Keywords: machining; minimum quantity lubrication; titanium; electrohydrodynamic atomization; end milling

\section{Introduction}

Grade 5 titanium alloy, Ti6Al4V, is the most used titanium alloy in industry and is extensively used in aerospace and medical implant applications. Ti6Al4V possesses high strength-to-weight ratio, high toughness and hardness as well as high corrosion resistance and biocompatibility [1]. It can maintain its mechanical properties at a wide range of temperatures, making it an ideal candidate for aerospace applications [2]. Together with poor thermal conductivity, these material properties are also responsible for making Ti6Al4V a difficult-to-machine material [3]. With its high strength and toughness, a large amount of energy is required during machining operations [4]. The majority of the energy used for material cutting transforms into heat at the cutting zone. Due to the short tool-chip contact length and poor thermal conductivity, high thermal loads and mechanical pressures are generated at the cutting zone. In machining titanium alloys, it is estimated that $80 \%$ of the heat is transferred into the cutting tool which can result in thermal softening and tribochemical wear leading to short tool life [5].

In order to control heat generation and dissipation in machining titanium alloys, low cutting parameters and abundant use of coolants/lubricants are recommended [5]. Cutting speed is the main factor affecting the cutting temperature. Opting for low cutting speeds results in low productivity and therefore, high manufacturing costs in machining titanium.

Denkena et al. [4] investigated the effect of various cutting parameters and coolant flow rate on power consumption and tool wear when machining Ti6Al4V. Kirsch et al. [6] investigated the effect of sub-zero cutting fluid, consisting of water and ethylene glycol at $-30{ }^{\circ} \mathrm{C}$ in turning Ti6Al4V. The analysis indicated that using sub-zero cutting fluids resulted in reduced cutting forces and tool 
wear. Bermingham et al. [7] found that cryogenic cooling with liquid nitrogen can improve the machinability of Ti6Al4V. However, they noted that controlling heat generation is more effective than heat removal when using cryogenic cooling. Cryogenic cooling using liquefied gases has shown benefits in improving tool life and surface finish in the machining of various difficult-to-machine materials [8,9]. Kaynak and Gharibi [10] investigated the cryogenic turning of Ti-5553 alloy at various cutting speeds ranging from 30 to $210 \mathrm{~m} / \mathrm{min}$ using liquid nitrogen and carbon dioxide cryogens. A maximum of $59 \%$ reduction in tool wear was reported when using liquid nitrogen at $210 \mathrm{~m} / \mathrm{min}$ cutting speed in comparison with dry turning.

Minimum quantity lubrication (MQL) has also gained significant attention as an alternative to conventional flood cooling [11,12]. Tanveer et al. [13] suggested using ultrasonic atomization for MQL turning of Ti6Al4V. Tascioglu et al. [14] investigated various cooling and lubrication methods for high speed turning of Ti-5553 titanium alloy at 90 and $120 \mathrm{~m} / \mathrm{min}$ cutting speeds. They reported that MQL has minimal impact on tool wear and cutting temperature in comparison with dry machining. High pressure coolant (HPC) at 50 bar pressure followed by liquid nitrogen cryogenic machining resulted in the longest tool life. Hu et al. [15] investigated the tool-wear mechanism in machining Ti6Al4V alloy and noted that tool wear is initiated with adhesion followed by diffusion and oxidation. These weakened the cutting edge and led to chipping. Nano and micro particles such as carbon nanotube, aluminum dioxide and tungsten disulfide were introduced into the lubricants in order to enhance tribological and thermal properties of the lubricants in MQL [16,17]. Reddy et al. [18] used electrostatic solid lubrication MQL for drilling AISI 4340. They reported improved tool life and overall drilling performance. Huang et al. [19] modified an MQL system by introducing a wire inside a conventional MQL nozzle for the electrostatic charging of lubricant oil. With the cutting tool as the opposite electrode, this formed a two-electrode electrostatic spraying setup. They reported that significant improvements were achieved in terms of tool-wear reduction in turning AISI 304 austenitic stainless steel. However, this setup is limited to low oil flow rates $(10-20 \mathrm{~mL} / \mathrm{h})$ and the nozzle is not necessarily optimized. Similar method was used by Shah et al. [20] for electrostatic MQL turning of 15-5 PH stainless steel. In their setup, they delivered the lubricant oil through a copper tube into the MQL nozzle to enhance conduction charging of the oil. Huang et al. [19] reported that using electrostatic charging, finer oil droplets are generated for MQL applications. Electrostatic and electrohydrodynamic methods have been used in various industries for generating sprays of fine droplets for various applications such as inkjet printers [21,22], fuel injection [23], microfluidic systems [24] and, pharmaceuticals [25,26].

In this paper, a novel cooling and lubrication system has been designed and realized based on the electrohydrodynamic atomization for minimum quantity lubrication (EHDA-MQL) in order to investigate the viability of EHDA-MQL in end milling Ti6Al4V alloy. A new EHDA-MQL nozzle in combination with the governing theory for EHDA is described and tested in end milling of Ti6Al4V alloy using solid carbide tools at $120 \mathrm{~m} / \mathrm{min}$ cutting speed. The performance of the nozzle is benchmarked against flood, compressed air machining and MQL using the same nozzle. The results for tool wear, tool life and power consumption are presented and discussed.

\section{Electrohydrodynamic Atomization Minimum Quantity Lubrication (EHDA-MQL) System}

A three-electrode setup was developed for EHDA of oil droplets in an MQL nozzle. The principle setup of the electrodes and the flow of oil and compressed air is shown in Figure 1. A nozzle with an exit orifice of $2 \mathrm{~mm}$ diameter was designed based on the physics of EHDA assisted with the flow of compressed air and manufactured by stereolithography 3D printing. In the setup, two copper electrodes $(1,2)$ were integrated inside the nozzle with cutting tool (3) acting as the third electrode. The distance between the electrodes inside the nozzle was $3 \mathrm{~mm}$. Since air breaks at around $3 \times 10^{6} \mathrm{kV} / \mathrm{m}$ and in order to increase the intensity of the electric field between electrode 1 and 2 , a polyurethane coated wire was used as the second electrode. The cathode and anode were connected to a high direct current (DC) voltage provided by a high voltage DC power supply with a maximum output voltage of $15 \mathrm{kV}$. 
A positive displacement pump was used to deliver the lubricant, rapeseed oil, into the nozzle. The oil is delivered at a flow rate of $280 \mathrm{~mL} / \mathrm{h}$ and the oil pump was capable of providing maximum $1 \mathrm{bar}$. Due to the pressure difference between the oil and air, lower flow rates could not be achieved by the positive displacement pump used. As shown in Figure 1, the oil is delivered through a central internal nozzle in contact with a copper electrode where it is mixed with pressurized air in an internal mixing channel. This results in initial atomization of the oil, forming droplets inside the nozzle. The oil is charged in contact with the copper electrode and is passed through the electric field established between the electrode 1 and 2. The oil is accelerated towards the nozzle's exit due the drag force by pressurized air and the electrostatic force imposed on the droplets. Based on Andrukh et al. [27], the electrostatic force can be estimated by:

$$
F_{e} \approx Q E
$$

where $F_{e}$ is electrostatic force, $Q$ is the droplet charge and $E$ is the intensity of the electric field.

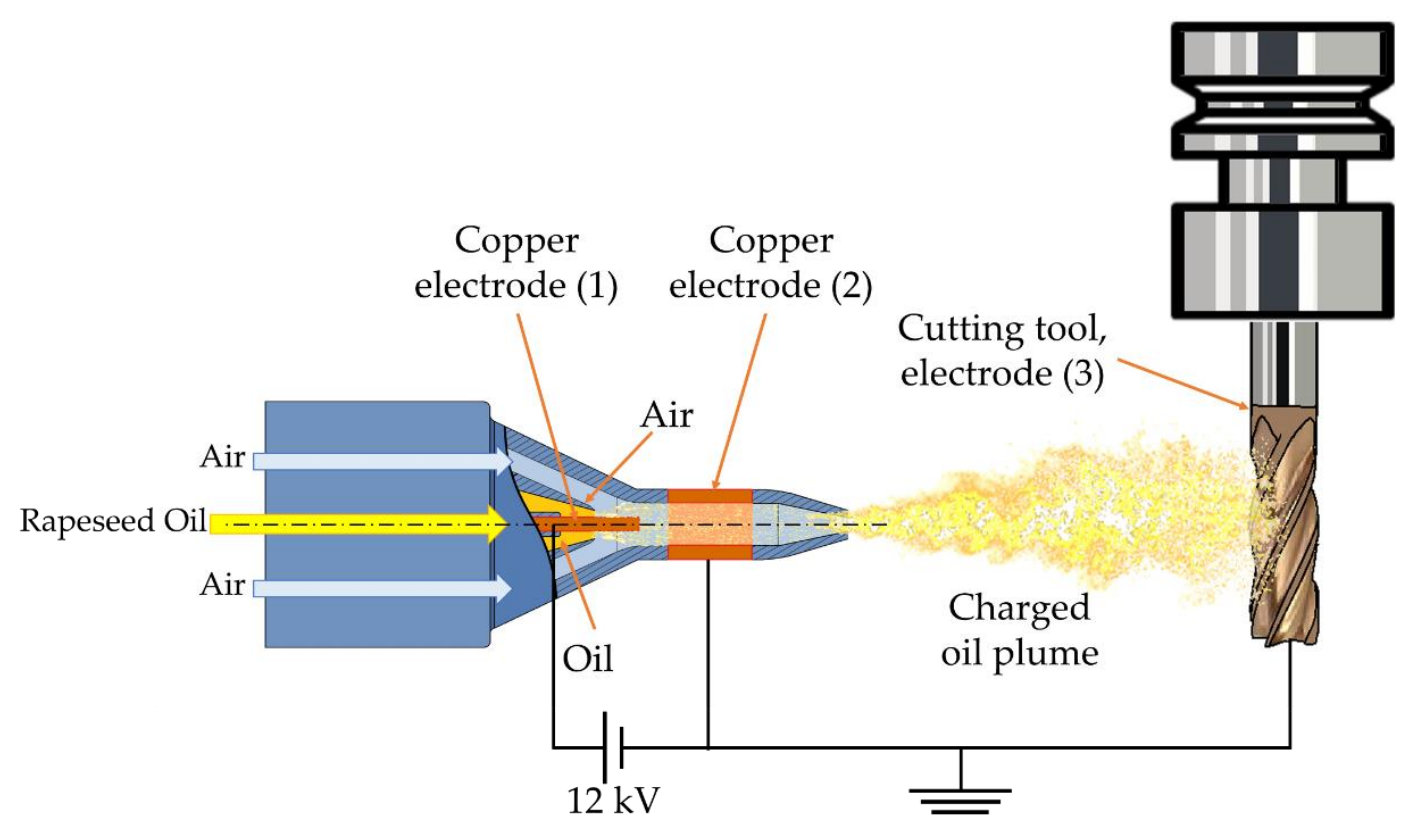

Figure 1. Schematic of Electrohydrodynamic Atomization Minimum Quantity Lubrication (EHDA-MQL) nozzle and machining setup (not to scale).

As the oil enters the nozzle, droplets are formed in contact with pressurized air flow. The droplets are pushed towards the nozzle's exit and move through the electric field established between electrodes. Surface charge is induced on the droplets passing through the electric field which can cause the droplets to disintegrate into smaller droplets as a result of Coulomb fission [28]. The flow of compressed air at 2 bar pressure and $44 \mathrm{~L} / \mathrm{min}$ flow rate together with electrostatic force carries the atomized oil towards the cutting tool. The air pressure was chosen based on the limitations of the supply system.

\section{Governing Theory}

EHDA is a process of breaking up a fluid jet into finer particles using an external electric field [29]. It exploits the repulsion between similar charges and attraction between opposite electrical charges to generate liquid droplets and accelerate them from one electrode towards another. In a simple two-electrode setup, the nozzle serves as one electrode and the target as the second electrode. Each electrode is connected to the opposite sides of a DC generator. The lubricant oil in contact with the nozzle is charged and then accelerated towards the charged target electrode as shown in Figure 2 [30]. The main weakness of the two-electrode setup is that effective atomization can only be achieved for 
very low liquid flow rates [23]. In a three-electrode setup, as used in this paper, an additional ring electrode is used between the nozzle electrode and the target. Both the ring electrode and the target are grounded which are used for charging and accelerating the droplets. In these systems, since the electrodes are not in contact with each other, a capacitance is formed between the electrodes. Pelesz and Czapka [31] developed the capacitance model for two- and three-electrode EHD systems as shown in Figure 2.
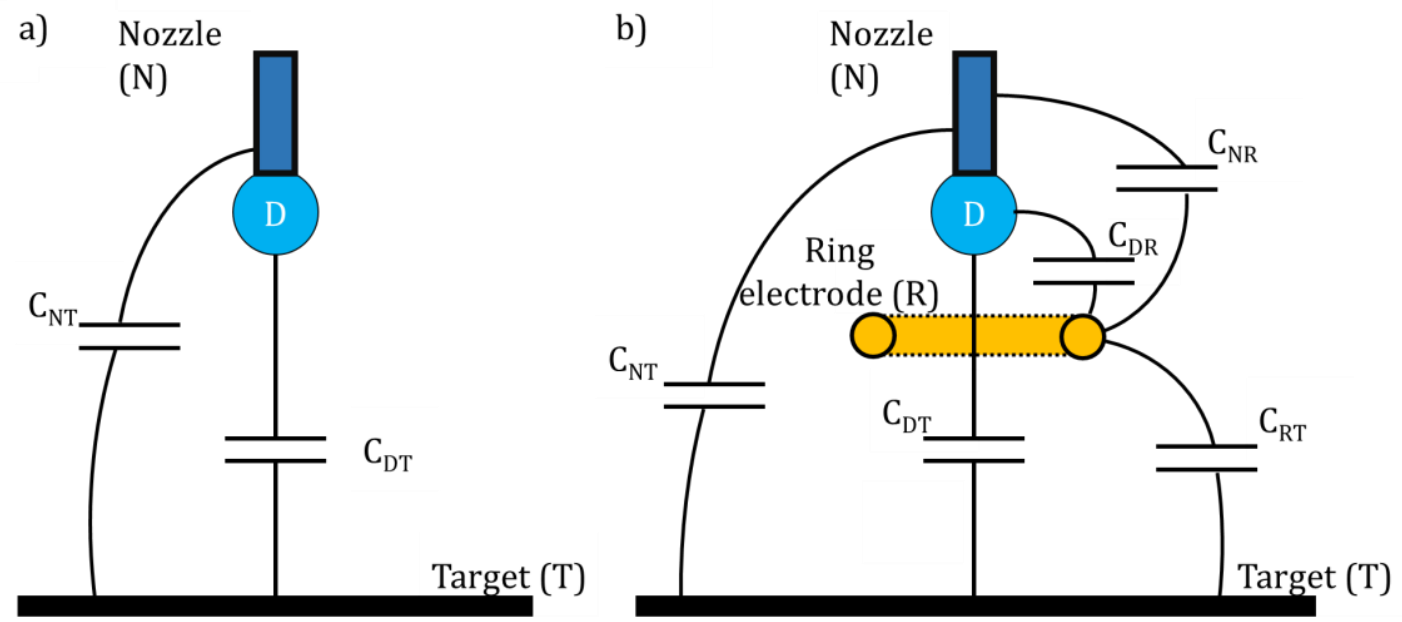

Figure 2. Capacitance model of a (a) two-electrode and (b) three-electrode EHDA setups with $C_{x y}$ indicating capacitance between $x$ and $y$ [31]. N: Nozzle electrode, R: Ring electrode, D: Droplet, T: Target electrode.

When a direct electric current is applied between two electrodes, the potential difference between the electrodes ionizes the molecules of air [32]. As a result of electrical potential difference, electrons are accelerated from the cathode towards the anode. In their path, the electrons collide with the molecules of air, releasing further electrons and ionizing the air. Electric charge is conducted to the oil in contact with the nozzle electrode. The electric field established between the electrodes induces surface charge onto the oil droplets as well as electrostatic force driving the oil towards the electrode with opposite charge [30].

If the intensity of the electric field between the electrodes becomes higher than the resistance of the air, undesirable electric discharge takes place, exacerbating the ionization condition. In atmospheric pressure, the intensity of the electric field can be controlled by the electric potential or the distance between the electrodes [33].

Therefore, the present system for EHDA-MQL has to work just below the breakdown voltage $\left(\mathrm{V}_{\mathrm{BK}}\right)$ which is the voltage above which electrical break takes place. This will ensure maximum electric field intensity between the electrodes.

The breakdown voltage within the investigated parameters is governed by Paschens' law [34] stating that the breakdown voltage (BDV) is a function of gas pressure $(p)$ and distance between the electrodes (d). Paschen's law is expressed as Equation (2) [35,36]:

$$
V_{B K}=\frac{B p d}{\ln (A p d)+\ln \left[\ln \left(1+\frac{1}{\gamma_{s e}}\right)\right]}
$$

where $V_{B K}$ is the breakdown voltage in volts, $p$ is the pressure of the gas in pascals, $d$ is the distance between the two electrodes in meters, $A$ is the saturation ionization of the gas at a specific electric stress per pressure $(E / P)$ and $B$ is an experimental constants based on gas excitation and ionization energies while $\gamma_{s e}$ is the second Townsend coefficient [37]. 
The presence of semi-dielectric oil droplets locally distorts the electric field and extends some of the electric field towards the surface of the droplets. Ions in the proximity of a dielectric droplet in the electric field are absorbed by the droplet's field of polarization, increasing its charge [38,39].

The Pauthenier's equation is a well-established model explaining the charge for solid dielectric particles in an electric field [40,41]:

$$
q(t)=4 \pi \varepsilon_{0}\left(1+2 \frac{\varepsilon_{r}-1}{\varepsilon_{r}+2}\right) R^{2} E \frac{e n k t}{4 \varepsilon_{0}+e n k t}
$$

where $q(t)$ is the charge carried by the single particle at time $t$ in the electric field, $\varepsilon_{0}$ is the absolute permittivity, $\varepsilon_{r}$ the relative permittivity of the material, $r$ the radius of the particle, $E$ the electric field strength, $e$ the charge of an electron, $n$ the electron concentration, $k$ the electron mobility and $t$ is the time the particle spent in the electric field.

Based on Pauthenier and Moreau-Hanot [40] the saturation charge $q_{\max }$ on a spherical droplet can be estimated using Equation (4) [42]:

$$
q_{\max }=4 \pi \varepsilon_{0} R^{2} \frac{3 \varepsilon_{r}}{\varepsilon_{r}+2} E
$$

Inculet et al. [43] reported that droplet distortion can occur in electric fields and their charge can exceed the saturation charge specified by Pauthenier's equation. The radius of a liquid droplet is dependent on the droplet's surface charge and surface tension. Charge accumulated in a droplet concentrates on its surface. If the mutual repulsive force becomes larger than the surface tension, then droplets will undergo Coulomb fission and explode into smaller droplets [28].

The magnitude of the charge where the repulsive force becomes larger than the surface tension for a single droplet of a conductive fluid is modelled by Rayleigh [39] and the equilibrium charge $q_{R}$ can be expressed by Equation (5). Rayleigh's model was later validated for dielectric droplets [44].

$$
q_{R}=8 \pi \sqrt{\varepsilon_{0} \vartheta_{L} r_{d}^{3}}
$$

where $\vartheta_{L}$ is surface tension and $r_{d}$ is droplet radius.

\section{Methodology}

\section{Experimental Setup}

The machining experiments consisted of end milling operation along blocks of Ti6Al4V $\alpha-\beta$ titanium alloy using coated solid carbide end mill cutting tools.

As explained in Section 2, the EHDA-MQL nozzle was manufactured using stereolithography $3 \mathrm{D}$ printing. The nozzle was held at $30^{\circ}$ inclination angle parallel to the helix of the cutting tool and $60^{\circ}$ to the machining path in tangent to the cutting zone using a custom-made holder attached to the spindle of a 3-axis CNC vertical milling center with a $13 \mathrm{~kW}$ spindle and maximum $8000 \mathrm{rpm}$. The distance between the nozzle and the cutting zone was $20 \mathrm{~mm}$. The setup is illustrated in Figure 3 . Pure rapeseed oil was used as a lubricant due to its good lubrication and thermal properties whilst also being a sustainable and biodegradable material eliminating the environmental issues related to cutting fluids $[45,46]$. According to Smith [47], fluids with surface tension larger than $0.05 \mathrm{Nm}^{-1}$ cannot be atomized using EHDA method. The rapeseed oil used for this investigation has a surface tension of $0.0329-0.03383 \mathrm{Nm}^{-1}$ [48] allowing for direct EHDA without a need for dilution with solvents. For the EHDA-MQL setup, air pressure at 2 bar and $44 \mathrm{~L} / \mathrm{m}$ flow rate was used. This was the maximum pressure that the positive displacement pump used for oil could manage whilst still delivering oil into the nozzle. The workpiece was secured on the machine tool table using MicroLoc system. The machine tool table, cutting tool and the workpiece were connected to the ground as shown in Figure 3. Oil was sprayed on a silicon wafer using the new nozzle and the droplets were measured using a microscope. 
The comparison between the oil with EHDA-MQL and MQL are shown in Figure 4a,b, respectively. Image processing in Matlab was used to measure the radius of the droplets generated by EHDA-MQL (Figure 4c) and the probability histogram of the droplets were developed as shown in Figure $4 \mathrm{~d}$. The analysis indicated that the droplets generated using EHDA-MQL have an average radius of $4.2 \mu \mathrm{m}$ with a median of $3.4 \mu \mathrm{m}$. The analysis showed that $78 \%$ of the EHDA-MQL droplets have radius smaller than $4 \mu \mathrm{m}$.
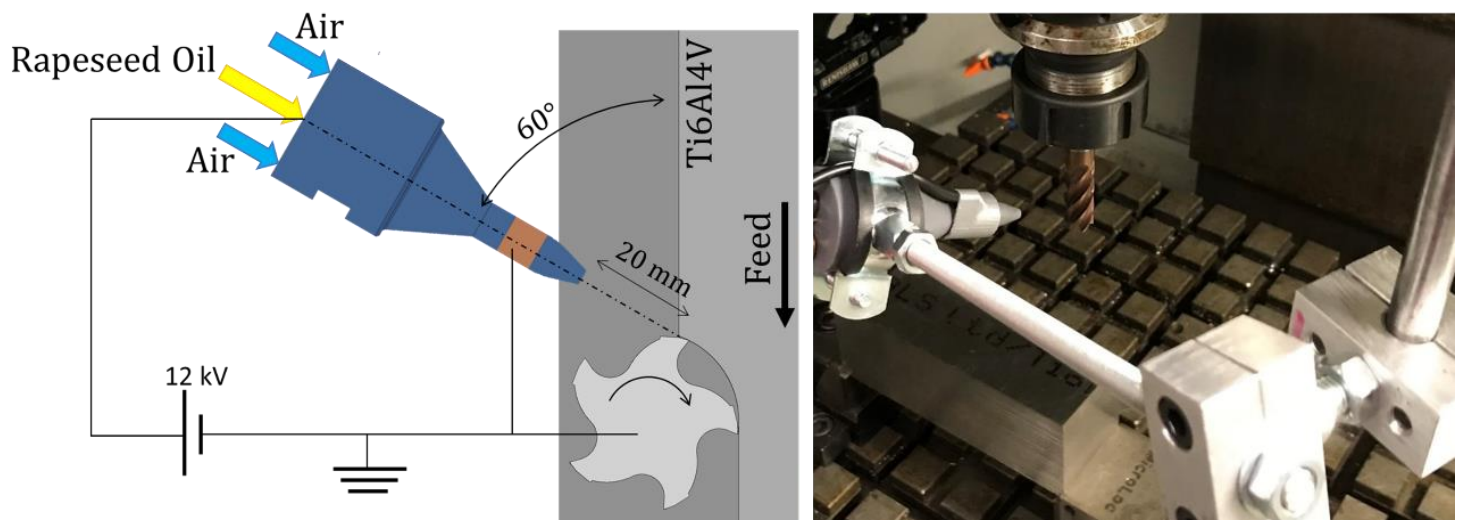

Figure 3. EHDA-MQL setup for milling experiments (electrical insulation is removed from the nozzle to show the setup).

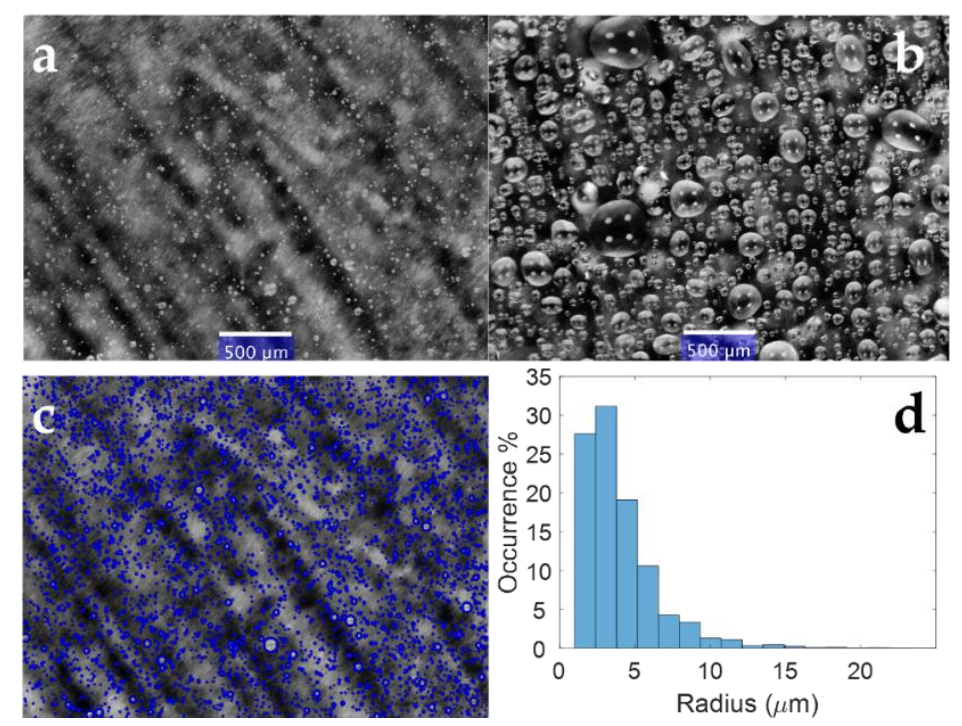

Figure 4. Microscopic images of droplets generated by (a) EHDA-MQL and (b) MQL, (c) image processing and (d) probability histogram of the droplet radius generated by EHDA-MQL.

The workpiece material used for the experiment was Ti6Al4V titanium alloy with average hardness of $285 \pm 15 \mathrm{HV}$ and dimensions of $50 \mathrm{~mm} \times 50 \mathrm{~mm} \times 150 \mathrm{~mm}$. The experiments were carried out on a 3 -axis vertical CNC machining center. The experiments were straight shoulder milling along the length of the titanium alloy workpiece using an end mill cutting tool. For each experiment, a new cutting tool was used. The cutting tools were $12 \mathrm{~mm}$ diameter and had $14^{\circ}$ rake angle with $10^{\circ} / 23^{\circ}$ primary and secondary relief angles and $30^{\circ}$ helix angle. The tools had 5 flutes and were manufactured from EMT 100 solid tungsten carbide with cobalt binder and had TiSiN coating [49] with an average thickness of $5 \mu \mathrm{m}$. The cutting parameters were kept constant for all machining experiments as shown in Table 1 . A high cutting speed of $120 \mathrm{~m} / \mathrm{min}$ was used to accelerate tool wear in order to reduce material consumption for the experiments. Successful machining at this speed also allows for a significant increase in productivity in machining Ti6Al4V. Each experiment was at least duplicated. 
Table 1. Cutting parameters used for experiments.

\begin{tabular}{ccc}
\hline Cutting Parameter & & Value (Unit) \\
\hline Cutting speed & $v_{c}$ & $120 \mathrm{~m} / \mathrm{min}$ \\
Chip load & $f_{z}$ & $0.05 \mathrm{~mm} /$ tooth \\
Spindle speed & $n$ & $3183 \mathrm{rpm}$ \\
Feed rate & $v_{f}$ & $796 \mathrm{~mm} / \mathrm{min}$ \\
Axial depth of cut & $a_{p}$ & $3 \mathrm{~mm}$ \\
Radial depth of cut & $a_{e}$ & $3 \mathrm{~mm}$ \\
Machining environment & & Flood, Air, MQL, EHDA-MQL \\
\hline
\end{tabular}

Four machining environments namely, (i) flood, (ii) air, (iii) MQL and (iv) EHDA-MQL, were investigated. Firstly, flood cooling with water soluble oil at $6 \%$ concentration was used to benchmark the tool life and surface roughness. The new nozzle was used for machining with compressed air at 2 bar and tool wear, tool life and power consumption were monitored in machining Ti6Al4V. The MQL machining experiment was conducted using the exact same setup whilst also using rapeseed oil at $0 \mathrm{~V}$ (no EHDA). For EHDA-MQL test, the identical setup and nozzle were used by including both oil and EHDA. The breaking voltage of the EHDA-MQL system was experimentally found to be $12 \mathrm{kV}$ by increasing the voltage from $0 \mathrm{~V}$ to $15 \mathrm{kV}$. When the electrical break voltage is reached, the voltage was reduced to just below the break voltage. This ensured maximum electrical intensity between the electrodes. For MQL and EHDA-MQL experiments, an oil flow rate of $283 \mathrm{~mL} / \mathrm{h}$ was used. This was the minimum flow rate that the positive displacement pump could provide. The position of the nozzle was maintained identical for compressed air, MQL and the EHDA-MQL to isolate the effect of the nozzle location.

Tool wear, tool life and surface roughness were monitored for the experiments following ISO 8688-2 [50] and BS EN ISO 4288 [51], respectively. The machining experiments were interrupted routinely and the tool wear was measured using a digital microscope. Surface roughness was measured using Taylor Hobson surface profilometer with a contact probe of $50 \mathrm{~nm}$ radius. The power consumption of the machine tool was measured during the experiments using Hioki 3169-20 hardwired into the machine tool at $1 \mathrm{~Hz}$ frequency. The power used for material cutting was calculated by removing the machine tool power consumption in air cutting from the power consumption when cutting material.

\section{Results and Discussion}

The results from flood cooling were used to benchmark tool wear and tool life. The new nozzle was used for compressed air experiments without oil and EHDA. The same nozzle and setup were used for MQL machining with oil. This indicates the contribution of oil lubrication on extending tool life and reducing power consumption. Moreover, an identical setup and nozzle was used for conducting EHDA-MQL machining experiments to clearly show the impact of EHDA on tool life and power consumption. The comparison between MQL and EHDA-MQL allows for the isolating of the effect of EHDA from that of MQL using the exact same setup, nozzle and lubricant. The tool wear was monitored throughout the experiments. As shown in Figure 5, the tool wear followed a similar pattern for all four machining environments. The tool wear grows rapidly at the start of the machining experiments reaching an average flank wear of 20-30 $\mu \mathrm{m}$. This is then followed by slow growth until the coating is removed exposing the tungsten carbide substrate at about 100-150 $\mu \mathrm{m}$ flank wear. After this point, the growth rate increases significantly leading to rapid tool failure. Flood cooling resulted in the shortest tool life of $706 \mathrm{~s}$ with catastrophic failure closely followed by compressed air with $746 \mathrm{~s}$ tool life. 


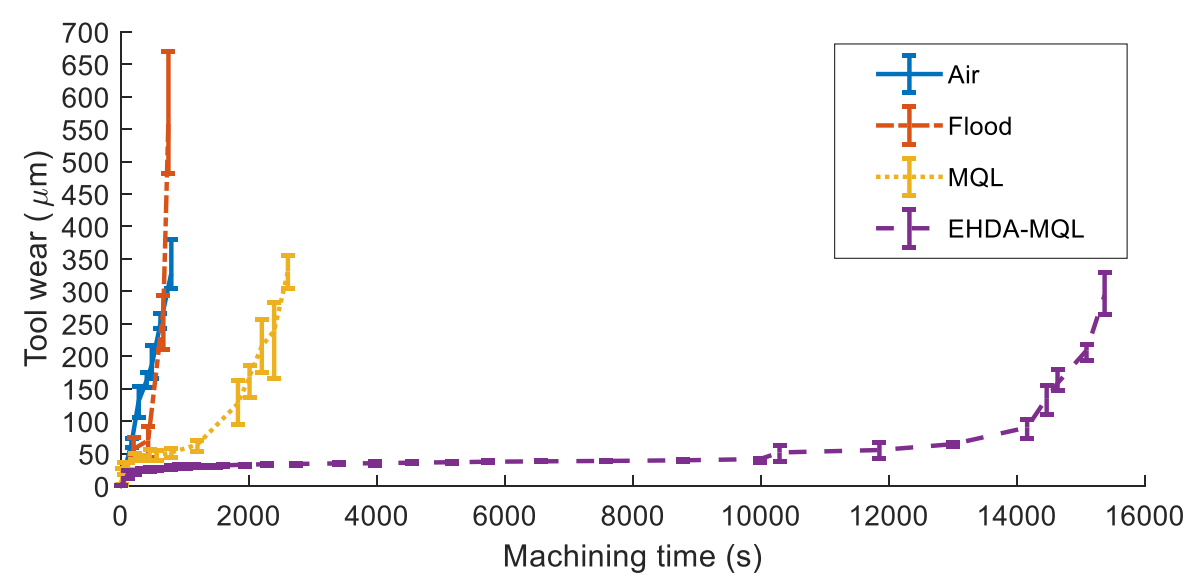

Figure 5. Tool-wear growth against machining time for various cooling-lubrication systems.

In compressed air, $44 \mathrm{~L} / \mathrm{min}$ of air at 2 bar pressure was targeted towards the cutting zone which translates to a speed of $233 \mathrm{~m} / \mathrm{s}$ at the nozzle exit with $2 \mathrm{~mm}$ diameter. The comparison between the tool life using flood cooling and compressed air indicates that the cooling capacity of compressed air surpasses the lubrication and cooling performance of flood cooling using water miscible coolants. This can potentially be explained by the low pressure of the machine tool's conventional flood cooling. At a high cutting speed, significant heat is generated at the cutting zone. In contact with hot surfaces, water-based coolant evaporates, forming a vapor barrier between the cutting zone and coolant due the Leiden frost effect [52]. In machining titanium, the cutting temperature is higher than the Leiden frost point of water [13]. Therefore, film boiling is the governing heat transfer mechanism [13]. Moreover, low pressure flood cooling system of the machine tool is aimed at flooding the cutting zone instead of penetrating the chip-tool contact area. Similar tool life for flood and air cooling has also been observed in the literature in the high-speed machining of Ti6Al4V [17].

The introduction of rapeseed oil into the stream of compressed air resulted in an improved tool life and reduced tool-wear growth. An average tool life of $2600 \mathrm{~s}$ was achieved when using MQL resulting in $229 \%$ and $268 \%$ increase in comparison with compressed air and flood cooling, respectively. The effect of rapeseed oil spray through compressed air can be categorized as (i) a reduction in heat generation and abrasion due to improved lubrication and reduced friction and (ii) improved heat removal due to evaporation and burning of oil at the cutting zone [17].

Within the first few machining passes, before the tool wear becomes significant, the power consumption was almost identical for Air and MQL. As soon as the coating is removed in the third machining pass and the substrate is exposed, the difference between power consumption in Air and MQL increases. This shows that the lubrication effect was minimal in the presence of the coating. However, when the substrate is exposed, the power consumption is $6 \%$ higher for Air than MQL. Assuming that $80 \%$ of the cutting energy transforms into heat, $4.8 \%$ less heat was generated in MQL. In addition, the existence of oil droplets in MQL enhances heat removal from the cutting zone further enhancing the machinability.

Using EHDA-MQL, delivering atomized rapeseed oil droplets through a stream of compressed air into the cutting zone yielded the longest average tool life of $15,370 \mathrm{~s}$. This is six times longer than that of MQL and 22 times longer than the tool life from conventional flood cooling. The average power consumption in the first $10 \mathrm{~s}$ of machining experiments was $17 \mathrm{VA}$ lower than MQL machining environment indicating improved lubrication. Performing the z-test on the data indicated that the difference is statistically significant. This indicates improved lubrication at the start of the machining experiment with sharp tools. EHDA is proven to generate fine droplets [53,54]. Huang et al. [19] reported that electrostatic charging of oil results in finer oil droplets in MQL application. Smaller sized droplets can penetrate the cutting zone and potentially enhance lubrication. It is also known that 
finer droplets enhance heat convective heat transfer $[17,55]$ which can improve heat removal from the cutting zone.

The power consumption for material cutting was calculated from the difference between power consumption when cutting material and when cutting air. As shown in Figure 6, the power required for cutting material increases as the tool wear grows. Due to the unpredictable power rush when the coolant pump is started, fluctuating power measurements were noted for flood machining experiments which made isolating the power consumption for material cutting in flood experiments unreliable. However, the general increasing trend in power consumption as a result of tool wear was identified. The power consumption in compressed air, MQL and EHDA-MQL started at around $280 \mathrm{~W}$ and gradually increased with the growth of tool wear. It reached the maximum of $554 \mathrm{~W}, 417 \mathrm{~W}$ and $452 \mathrm{~W}$ at the end of the tool life for air, MQL and EHDA-MQL, respectively. A statistical $t$-test was performed on the results, and it indicated a statistically significant difference between the power consumption for various experiments specifically at the start of the machining experiments where the impact of tool wear is negligible.

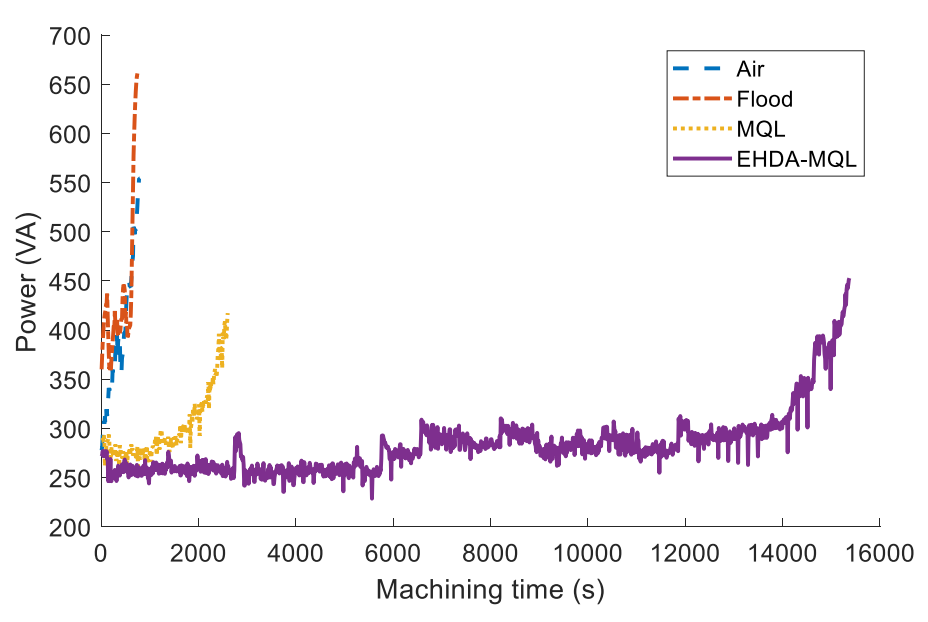

Figure 6. Power consumption for material cutting for various cooling-lubrication systems.

In order to identify the impact of lubrication on machining whilst taking the effect of tool wear into account, the graph of tool wear against power consumption for each machining experiment together with relative trendlines was developed as shown in Figure 7. From Figure 7, it is clear that when tool wear is less than $60 \mu \mathrm{m}$, EHDA-MQL outperforms all machining environments in terms of power consumption. However, after this point, MQL registered the lowest power consumption based on tool wear. It can be observed that the lubrication effect of EHDA-MQL system is limited to specific conditions. In contrast, the improvements in tool life is potentially due to the improved cooling effect as a result of finer droplets generated through EHDA. Enhanced heat removal from the cutting zone, prevents thermochemical tool wear and potentially delays tool-wear growth.

Micrographs of the cutting tools were generated at the end of the tool life. Figure 8a-d illustrate the tool wear for various experiments at the tool nose whilst Figure 8e,f show the tool wear at the depth of cut for MQL and EHDA-MQL conditions. As shown in Figure 8a,b, the tool wear was distributed along the flank face of the tool in flood and compressed air environments. However, in MQL and EHDA-MQL, the tool wear was concentrated at the depth of cut as illustrated in Figure 8e,f. The adhesion of the workpiece material and cutting chips was detected in all machining experiments. At high cutting speeds and temperatures, diffusion wear was observed. Similar observations regarding tool wear were also reported by Denkena et al. [4] in machining Ti6Al4V. The adhered material onto the rake face of the tool was removed by the flow of cutting chips resulting in crater wear. Crater wear close to the cutting edge was dominant in all machining experiments leading to chipping of the cutting edge. Hu et al. [15] reported that tool wear in milling Ti6Al4V was a combination of adhesion, chipping 
and diffusion. Minor oxidation was also noted. Adhesion and diffusion wear are commonly reported in machining titanium alloys [56].

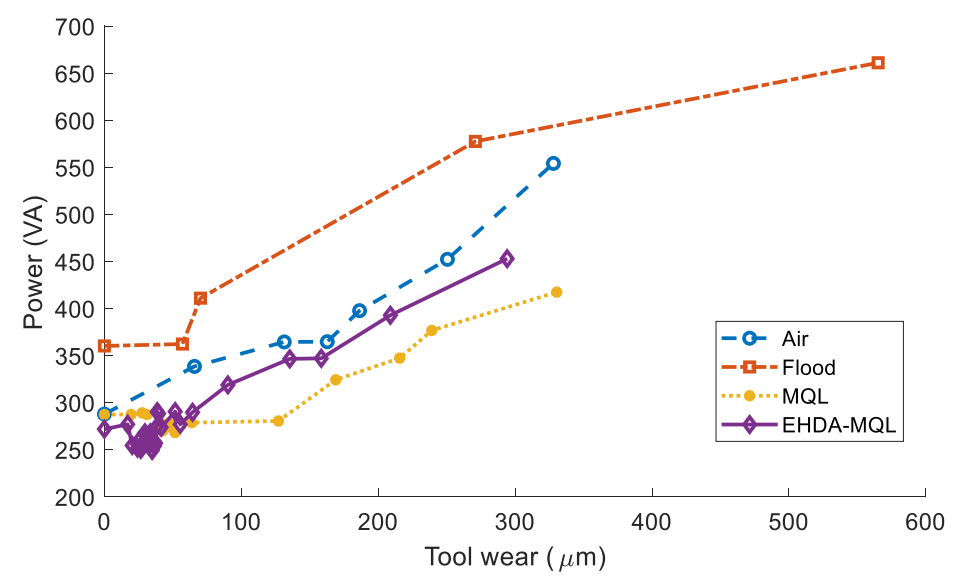

Figure 7. Power consumption against tool wear for various cooling-lubrication methods.

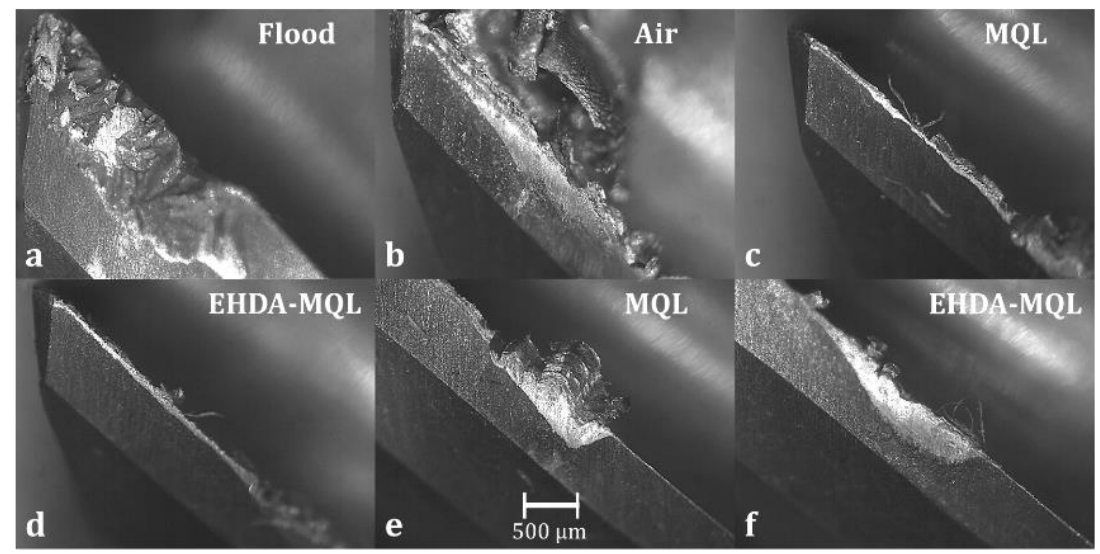

Figure 8. Cutting tool flank face at the end of tool life in each experiment.

The introduction of rapeseed oil effectively delayed the adhesion and formation of crater wear in MQL and EHDA-MQL experiments. The EHDA of the rapeseed oil delayed chipping and adhesion wear for over $170 \mathrm{~min}$ into the machining experiments. Fine oil droplets were generated using EHDA-MQL. It has been reported that finer droplets enhance heat transfer [55] and penetrability into the cutting zone [57]. An example of the timeline of tool wear and events leading to tool failure for EHDA-MQL experiments is shown in Figure 9. The tool wear was initiated with a chipping exposing the tungsten carbide substrate. At high cutting speeds and cutting temperatures, WC is vulnerable to chemical reaction with titanium workpiece material. This led to adhesion and subsequent crater wear formation. The crater is then filled with the workpiece material and built up edge (BUE). The BUE is removed with the flow of chips taking parts of the substrate leaving a larger crater and weakening the cutting edge. This is then followed by further chipping and loss of material on the flank face.

A blunt cutting edge requires more power for material cutting, hence higher temperatures are generated at the cutting zone. A higher temperature results in increased chemical affinity between the workpiece and cutting tool material and reduces the material strength and hardness of the cutting tool. The power consumption was increased from $296 \mathrm{~W}$ at $10,292 \mathrm{~s}$ to $439 \mathrm{~W}$ at $15,371 \mathrm{~s}$, an increase of $48 \%$. The surface roughness was measured for all machining experiments and the average roughness was calculated. The surface roughness increased from $0.3 \mu \mathrm{m}$ at the start of the experiments to $0.6 \mu \mathrm{m}$ as the wear progressed for all experiments irrespective of machining environment. Performing the $t$-test, no statistically significant difference was detected between the measurements for surface roughness. 


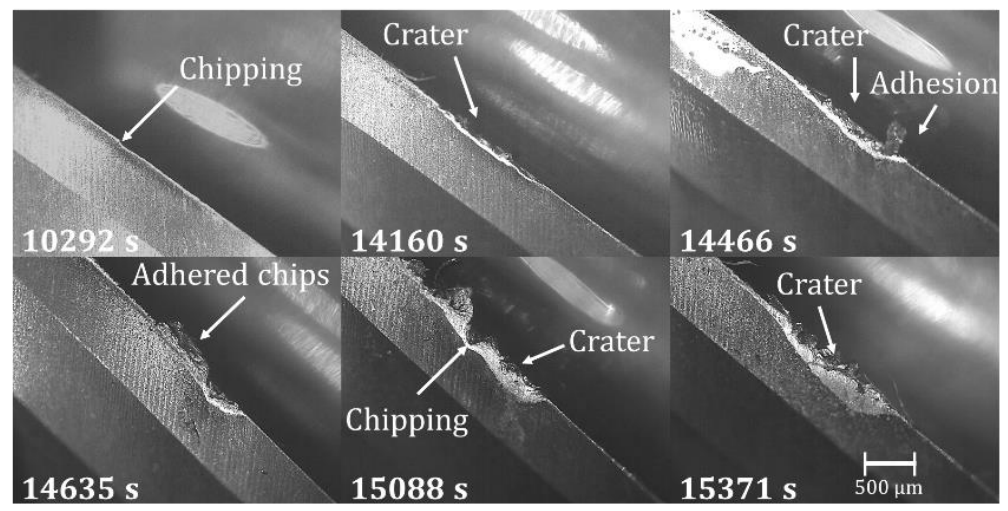

Figure 9. Growth of tool wear in EHDA-MQL environment against machining time.

This initial investigation indicated the potential and viability of EHDA for MQL machining of Ti6Al4V. Further investigations are necessary to establish the improvement mechanism and the impact of charge effect on machining performance. The analysis indicated the potential of EHDA in generating fine lubricant droplets. However, further analysis is required to optimize and provide precise control over droplet dimensions and their impact on machining performance. Only a limited set of parameters both for the EHDA-MQL and machining experiments were used. A wider analysis is required to investigate the interactions between various parameters. Specifically, the impact of voltage, polarity, flow rate and pressure require further investigation and optimization. In addition, the distance and position of the nozzle from the cutting zone have significant effect on machining performance which will be investigated in future works. The underlying science of EHDA is provided in this paper. Further studies are required to refine these analyses for the specific MQL application taking into account the impact of pressurized air and drag through computational fluid dynamic analysis.

\section{Conclusions}

A new electrohydrodynamic atomization system for MQL lubrication and cooling was presented for machining Ti6Al4V alloy. The major novelty of the system is the use of a three-electrode setup aiming to enhance atomization of oil droplets. The EHDA-MQL system was manufactured and tested through a series of machining experiments. The performance of the system was benchmarked against flood cooling, MQL and air cooling using an identical setup to the EHDA-MQL system. The new EHDA-MQL is capable of generating fine droplets with median radius of $3.4 \mu \mathrm{m}$. The analysis indicated that the EHDA-MQL can extend the tool life as much as 6 and 22 times when compared with MQL and flood cooling whilst maintaining a similar surface roughness. The improved performance is attributed to enhanced heat removal due to fine droplets generated by EHDA, resulting in reduced tool-wear growth rate. The results provide promising potential for increased productivity through realizing higher cutting speeds for machining Ti6Al4V.

Author Contributions: Conceptualization, A.S.; methodology, A.D.B. and A.S.; software, A.S.; validation, A.D.B. and A.S.; formal analysis, A.S.; investigation, A.D.B. and A.S.; resources, A.S.; data curation, A.S.; writing - original draft preparation, A.D.B. and A.S.; writing—review and editing, A.S.; visualization, A.D.B. and A.S.; supervision, A.S.; project administration, A.S.; funding acquisition, A.S. Both authors have read and agreed to the published version of the manuscript.

Funding: This research was funded by Innovate UK, grant number 133699.

Acknowledgments: The authors would like to acknowledge the support of Evripides Loukaides for SLA printing of the nozzle.

Conflicts of Interest: The authors declare no conflict of interest. 


\section{References}

1. Umbrello, D.; Rotella, G. Fatigue life of machined ti6al4v alloy under different cooling conditions. CIRP Ann. 2018, 67, 99-102. [CrossRef]

2. Hojati, F.; Daneshi, A.; Soltani, B.; Azarhoushang, B.; Biermann, D. Study on machinability of additively manufactured and conventional titanium alloys in micro-milling process. Precis. Eng. 2020, 62, 1-9. [CrossRef]

3. Wyen, C.F.; Wegener, K. Influence of cutting edge radius on cutting forces in machining titanium. CIRP Ann. 2010, 59, 93-96. [CrossRef]

4. Denkena, B.; Helmecke, P.; Hülsemeyer, L. Energy efficient machining of Ti-6Al-4V. CIRP Ann. 2015, 64, 61-64. [CrossRef]

5. Pervaiz, S.; Anwar, S.; Qureshi, I.; Ahmed, N. Recent advances in the machining of titanium alloys using minimum quantity lubrication (MQL) based techniques. Int. J. Precis. Eng. Manuf. Green Technol. 2019, 6, 133-145. [CrossRef]

6. Kirsch, B.; Basten, S.; Hasse, H.; Aurich, J.C. Sub-zero cooling: A novel strategy for high performance cutting. CIRP Ann. 2018, 67, 95-98. [CrossRef]

7. Bermingham, M.J.; Kirsch, J.; Sun, S.; Palanisamy, S.; Dargusch, M.S. New observations on tool life, cutting forces and chip morphology in cryogenic machining Ti-6Al-4V. Int. J. Mach. Tools Manuf. 2011, 51, 500-511. [CrossRef]

8. Jawahir, I.S.; Attia, H.; Biermann, D.; Duflou, J.; Klocke, F.; Meyer, D.; Newman, S.T.; Pusavec, F.; Putz, M.; Rech, J.; et al. Cryogenic manufacturing processes. CIRP Ann. 2016, 65, 713-736. [CrossRef]

9. Dix, M.; Wertheim, R.; Schmidt, G.; Hochmuth, C. Modeling of drilling assisted by cryogenic cooling for higher efficiency. CIRP Ann. Manuf. Technol. 2014, 63, 73-76. [CrossRef]

10. Kaynak, Y.; Gharibi, A. Cryogenic machining of titanium Ti-5553 alloy. J. Manuf. Sci. Eng. 2019, 141, 041012. [CrossRef]

11. Rahim, E.A.; Ibrahim, M.R.; Rahim, A.A.; Aziz, S.; Mohid, Z. Experimental investigation of minimum quantity lubrication (MQL) as a sustainable cooling technique. Procedia CIRP 2015, 26, 351-354. [CrossRef]

12. M'Saoubi, R.; Axinte, D.; Soo, S.L.; Nobel, C.; Attia, H.; Kappmeyer, G.; Engin, S.; Sim, W.-M. High performance cutting of advanced aerospace alloys and composite materials. CIRP Ann. 2015, 64, 557-580. [CrossRef]

13. Tanveer, A.; Marla, D.; Kapoor, S.G. A thermal model to predict tool temperature in machining of Ti-6Al-4V alloy with an atomization-based cutting fluid spray system. J. Manuf. Sci. Eng. 2017, 139, 071016. [CrossRef]

14. Tascioglu, E.; Gharibi, A.; Kaynak, Y. High speed machining of near-beta titanium Ti-5553 alloy under various cooling and lubrication conditions. Int. J. Adv. Manuf. Technol. 2019, 102, 4257-4271. [CrossRef]

15. Hu, M.; Ming, W.; An, Q.; Chen, M. Tool wear monitoring in milling of titanium alloy Ti-6Al-4V under MQL conditions based on a new tool wear categorization method. Int. J. Adv. Manuf. Technol. 2019, 104, 4117-4128. [CrossRef]

16. Hegab, H.; Umer, U.; Deiab, I.; Kishawy, H. Performance evaluation of Ti-6Al-4V machining using nano-cutting fluids under minimum quantity lubrication. Int. J. Adv. Manuf. Technol. 2018, 95, 4229-4241. [CrossRef]

17. Shokrani, A.; Betts, J. A new hybrid minimum quantity lubrication system for machining difficult-to-cut materials. CIRP Ann. 2020. [CrossRef]

18. Narala, S.K.R.; Nouari, M.; Yang, M. Development of electrostatic solid lubrication system for improvement in machining process performance. Int. J. Mach. Tools Manuf. 2010, 50, 789-797.

19. Huang, S.; Lv, T.; Wang, M.; Xu, X. Effects of machining and oil mist parameters on electrostatic minimum quantity lubrication-EMQL turning process. Int. J. Precis. Eng. Manuf. Green Technol. 2018, 5, 317-326. [CrossRef]

20. Shah, P.; Khanna, N.; Zadafiya, K.; Bhalodiya, M.; Maruda, R.W.; Krolczyk, G.M. In-house development of eco-friendly lubrication techniques (EMQL, nanoparticles + EMQL and EL) for improving machining performance of 15-5 phss. Tribol. Int. 2020, 151, 106476. [CrossRef]

21. Chen, F.; Lin, L.; Zhang, J.; He, Z.; Uchiyama, K.; Lin, J.-M. Single-cell analysis using drop-on-demand inkjet printing and probe electrospray ionization mass spectrometry. Anal. Chem. 2016, 88, 4354-4360. [CrossRef]

22. Vespini, V.; Coppola, S.; Todino, M.; Paturzo, M.; Bianco, V.; Grilli, S.; Ferraro, P. Forward electrohydrodynamic inkjet printing of optical microlenses on microfluidic devices. Lab Chip 2016, 16, 326-333. [CrossRef] 
23. Lehr, W.; Hiller, W. Electrostatic atomization of liquid hydrocarbons. J. Electrost. 1993, 30, 433-440. [CrossRef]

24. Russel, M.K.; Selvaganapathy, P.R.; Ching, C.Y. Ion drag electrohydrodynamic (EHD) micro-pumps under a pulsed voltage. J. Electrost. 2016, 82, 48-54. [CrossRef]

25. Nguyen, D.N.; Clasen, C.; Van den Mooter, G. Pharmaceutical applications of electrospraying. J. Pharm. Sci. 2016, 105, 2601-2620. [CrossRef] [PubMed]

26. Arzi, R.S.; Sosnik, A. Electrohydrodynamic atomization and spray-drying for the production of pure drug nanocrystals and co-crystals. Adv. Drug Deliv. Rev. 2018, 131, 79-100. [CrossRef]

27. Andrukh, T.; Rubin, B.; Kornev, K.G. Wire-in-a-nozzle as a new droplet-on-demand electrogenerator. Langmuir 2011, 27, 3206-3210. [CrossRef]

28. Li, K.-Y.; Tu, H.; Ray, A.K. Charge limits on droplets during evaporation. Langmuir 2005, 21, 3786-3794. [CrossRef]

29. Xie, J.; Jiang, J.; Davoodi, P.; Srinivasan, M.P.; Wang, C.-H. Electrohydrodynamic atomization: A two-decade effort to produce and process micro-/nanoparticulate materials. Chem. Eng. Sci. 2015, 125, 32-57. [CrossRef]

30. Zhao, S.; Castle, G.S.P.; Adamiak, K. Comparison of conduction and induction charging in liquid spraying. J. Electrost. 2005, 63, 871-876. [CrossRef]

31. Pelesz, A.; Czapka, T. Empirical and numerical analysis of conduction and induction charging of droplets in a three-electrode system. Energies 2020, 13, 469. [CrossRef]

32. Cooray, V. 3.4 corona discharges. In Lightning Electromagnetics; Institution of Engineering and Technology: London, UK, 2012; pp. 67-85.

33. Druyvesteyn, M.; Penning, F.M. The mechanism of electrical discharges in gases of low pressure. Rev. Mod. Phys. 1940, 12, 87. [CrossRef]

34. Lüttgens, G.; Lüttgens, S.; Schubert, W. M11.1 resistance R0 (object or material). In Static Electricity—Understanding, Controlling, Applying; John Wiley \& Sons: Hoboken, NJ, USA, 2017.

35. Lieberman, M.A.; Lichtenberg, A.J. Principles of Plasma Discharges and Materials Processing; John Wiley \& Sons: Hoboken, NJ, USA, 2005.

36. Loveless, A.M.; Meng, G.; Ying, Q.; Wu, F.; Wang, K.; Cheng, Y.; Garner, A.L. The transition to paschen's law for microscale gas breakdown at subatmospheric pressure. Sci. Rep. 2019, 9, 5669. [CrossRef] [PubMed]

37. Husain, E.; Nema, R.S. Analysis of paschen curves for air, N2 and SF6 using the townsend breakdown equation. IEEE Trans. Electr. Insul. 1982, EI-17, 350-353. [CrossRef]

38. Mizuno, A. Electrostatic precipitation. IEEE Trans. Dielectr. Electr. Insul. 2000, 7, 615-624. [CrossRef]

39. Rayleigh, L. XX. On the equilibrium of liquid conducting masses charged with electricity. Lond. Edinb. Dublin Philos. Mag. J. Sci. 1882, 14, 184-186. [CrossRef]

40. Pauthenier, M.; Moreau-Hanot, M. La charge des particules sphériques dans un champ ionisé. J. Phys. Radium 1932, 3, 590-613. [CrossRef]

41. Goldwater, D.; Stickler, B.; Martinetz, L.; Northup, T.E.; Hornberger, K.; Millen, J. Levitated electromechanics: All-electrical cooling of charged nano- and micro-particles. Quantum Sci. Technol. 2018, 4, 024003. [CrossRef]

42. Adamiak, K. Rate of charging of spherical particles by monopolar ions in electric fields. IEEE Trans. Ind. Appl. 2002, 38, 1001-1008. [CrossRef]

43. Inculet, I.I.; Adamiak, K. Charge limits in corona charging of distorted liquid droplets. IEEE Trans. Ind. Appl. 1993, 29, 1058-1061. [CrossRef]

44. Carroll, C. Small oscillations of a liquid drop with surface charge. J. Phys. A Math. Gen. 1978, 11, 225. [CrossRef]

45. Lawal, S.A.; Choudhury, I.A.; Nukman, Y. Application of vegetable oil-based metalworking fluids in machining ferrous metals-A review. Int. J. Mach. Tools Manuf. 2012, 52, 1-12. [CrossRef]

46. Deiab, I.; Raza, S.W.; Pervaiz, S. Analysis of lubrication strategies for sustainable machining during turning of titanium ti-6al-4v alloy. Procedia CIRP 2014, 17, 766-771. [CrossRef]

47. Smith, D.P.H. The electrohydrodynamic atomization of liquids. IEEE Trans. Ind. Appl. 1986, IA-22, 527-535. [CrossRef]

48. Melo-Espinosa, E.A.; Sánchez-Borroto, Y.; Errasti, M.; Piloto-Rodríguez, R.; Sierens, R.; Roger-Riba, J.; Christopher-Hansen, A. Surface tension prediction of vegetable oils using artificial neural networks and multiple linear regression. Energy Procedia 2014, 57, 886-895. [CrossRef]

49. IonBond. Hardcut-Tisin Multilayer Coating. Available online: https:/www.ionbond.com/coating-services/ cutting-tools/hardcut/ (accessed on 11 July 2020). 
50. International Organization for Standardization. Tool Life Testing in Milling_Part 2: End Milling; ISO-8688-2; International Organization for Standardization: Geneva, Switzland, 1989.

51. British Standard Institute. Geometric product specification (GPS). In Surface Texture—Profile Method: Rules and Procedures for the Assessment of Surface Texture; BS-EN-ISO-4288; British Standard Institute: London, UK, 1998.

52. Jäger, H.; Alagan, N.T.; Holmberg, J.; Beno, T.; Wretland, A. Eds analysis of flank wear and surface integrity in machining of alloy 718 with forced coolant application. Procedia CIRP 2016, 45, 271-274. [CrossRef]

53. Balachandran, W.; Miao, P.; Xiao, P. Electrospray of fine droplets of ceramic suspensions for thin-film preparation. J. Electrost. 2001, 50, 249-263. [CrossRef]

54. Kelly, A.J. Charge injection electrostatic atomizer modeling. Aerosol Sci. Technol. 1990, 12, 526-537. [CrossRef]

55. Kumari, N.; Bahadur, V.; Hodes, M.; Salamon, T.; Kolodner, P.; Lyons, A.; Garimella, S.V. Analysis of evaporating mist flow for enhanced convective heat transfer. Int. J. Heat Mass Transf. 2010, 53, 3346-3356. [CrossRef]

56. Saketi, S.; Odelros, S.; Östby, J.; Olsson, M. Experimental study of wear mechanisms of cemented carbide in the turning of Ti6Al4V. Materials 2019, 12, 2822. [CrossRef]

57. Park, K.-H.; Olortegui-Yume, J.; Yoon, M.-C.; Kwon, P. A study on droplets and their distribution for minimum quantity lubrication (MQL). Int. J. Mach. Tools Manuf. 2010, 50, 824-833. [CrossRef]

(C) 2020 by the authors. Licensee MDPI, Basel, Switzerland. This article is an open access article distributed under the terms and conditions of the Creative Commons Attribution (CC BY) license (http://creativecommons.org/licenses/by/4.0/). 